\title{
Corrosion Inhibition of Aluminum-Silicon Alloy in Hydrochloric Acid Solutions Using Carbamidic Thioanhydride Derivatives
}

\author{
A. S. Fouda ${ }^{1}$ F. Sh. Mohamed ${ }^{2} \cdot$ M. W. El-Sherbeni ${ }^{1}$
}

Received: 10 January 2016/Revised: 6 March 2016/Accepted: 17 March 2016/Published online: 15 April 2016

(C) Springer International Publishing Switzerland 2016

\begin{abstract}
The corrosion inhibition of Al-Si alloy in $1 \mathrm{M}$ $\mathrm{HCl}$ solution using some carbamidic thioanhydride derivatives at various concentrations has been studied using potentiodynamic polarization, electrochemical impedance spectroscopy, electrochemical frequency modulation, and hydrogen evolution techniques. Results obtained indicate that the inhibition efficiency $(\% \eta)$ reached $94 \%$ at $2 \times 10^{-5} \mathrm{M}$ concentration and was found to increase with increasing the inhibitor concentrations. $\% \eta$ decreased with increasing the temperature. Potentiodynamic polarization curves showed that the investigated derivatives were mixed-type inhibitors. Some activation and adsorption thermodynamic parameters $(\Delta H, \Delta G$, and $\Delta S)$ were calculated and discussed. The adsorption of these derivatives on the alloy surface was found to obey Langmuir adsorption isotherm. The electrochemical results are in good agreement with the calculated quantum chemical HOMO and LUMO energies of the tested molecules.
\end{abstract}

Keywords Carbamidic thioanhydride derivatives $\cdot \mathrm{Al}-\mathrm{Si}$ alloy $\cdot \mathrm{HCl} \cdot$ Potentiodynamic polarization - EIS - EFM · Hydrogen evolution

\section{Introduction}

Corrosion of aluminum and its alloys has been a subject of numerous studies due to their high technological value, its strength, electrical conductivity, super purity [1], and wide

A. S. Fouda

asfouda@hotmail.com

1 Department of Chemistry, Faculty of Science, Mansoura University, Mansoura 35516, Egypt

2 Department of Chemistry, Faculty of Science, Damietta University, Damietta, Egypt range of industrial applications especially in construction, electronics, packing, and transportation. $1 \mathrm{M}$ hydrochloric acid solution is used for pickling, chemical, and electrochemical etching of aluminum and its alloys. Although $\mathrm{Al}$ has an adhesive protective passivating oxide film, but this surface film is amphoteric and etching when the metal is exposed to high concentrations of acids or bases [2]. The main aim of many researchers is to protect the metal from corrosive agents, so it is very important to add corrosion inhibitors to prevent metal corrosion and minimize acid consumption [3]. Generally, the first step in the action mechanism of the inhibitors in aggressive acid media is the adsorption of the inhibitors on the metal surface. Various mechanisms have been proposed to explain the breakdown of the passive oxide film when chloride reaches the metal film interface. Recently, it has shown that chloride does not enter the oxide film but it is chemisorbed on the oxide surface [4]. The choice of inhibitor is based on two considerations: first, it could be synthesized conveniently from relatively cheap raw materials; second, it contains the electron cloud on the aromatic ring or electro-negative atoms such as nitrogen and oxygen in relatively long-chain compounds. In general, organic compounds with oxygen, sulfur, and/or nitrogen as polar groups and conjugated double bonds in their structures have been reported to be good corrosion inhibitors for many metals and alloys in corrosive media [5-23]. Polar functional are regarded as the reaction center that stabilizes the adsorption process [24]. The adsorption process depends on a few factors, such as the nature and surface charge of the metal, the adsorption mode, the chemical structure of the metal, and the type of the electrolyte solution [25].

The aim of the present work is to study: (i) the effect of the addition of some carbamidic thioanhydride derivatives on the behavior of Al-Si alloy corrosion in $1 \mathrm{M}$ hydrochloric acid solution using chemical and electrochemical techniques, (ii) 
Table 1 Structures, names, formulas, and molecular weights of the studied carbamidic thioanhydride derivatives

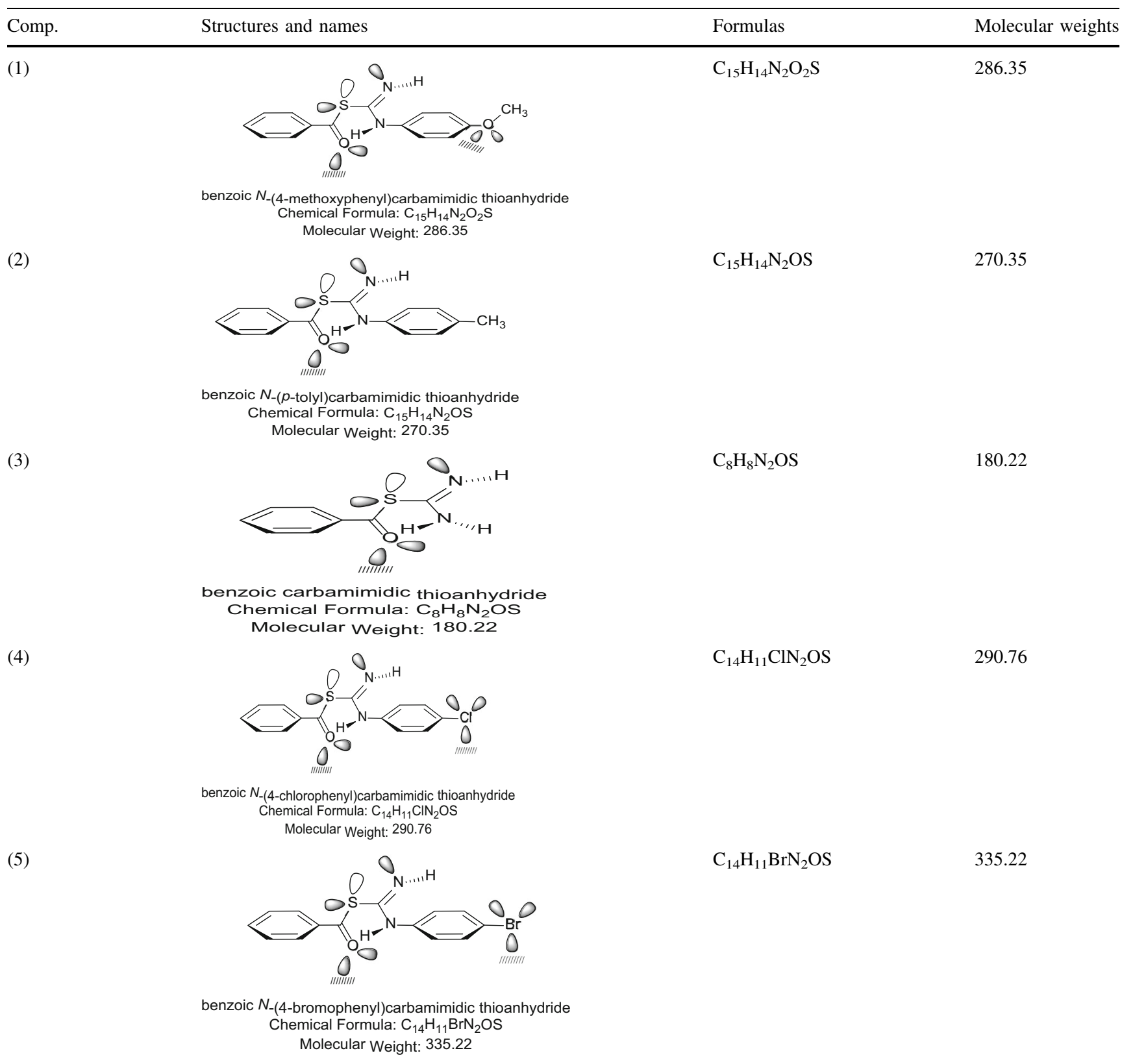

the effect of temperature on the inhibition efficiency, and (iii) elucidate the corrosion mechanism.

\section{Experimental}

\subsection{Materials and Reagents}

Al-Si alloy that used in this study is of chemical composition: $92.482 \% \mathrm{Al}, 7.030 \% \mathrm{Si}, 0.100 \% \mathrm{Fe}, 0.003 \% \mathrm{Mn}$, $0.369 \% \mathrm{Mg}, 0.002 \% \mathrm{Ni}, 0.001 \% \mathrm{Cr}, 0.003 \% \mathrm{Zn}$, $0.003 \% \mathrm{Na}$, and $0.007 \% \mathrm{Ti}$. carbamidic thioanhydride derivatives studied in this work have the structures and molecular weights listed in Table 1. Appropriate concentration of acid ( $\mathrm{HCl} 37 \%)(1 \mathrm{M})$ was prepared by using bidistilled water. $1 \times 10^{-3} \mathrm{M}$ stock solutions from the investigated compounds were prepared by dissolving the appropriate weights of the used chemically pure solid compounds in absolute ethanol.

\subsection{Electrochemical Analysis}

\subsubsection{Potentiodynamic Polarization Technique}

Potentiodynamic measurements were conducted in a conventional three-electrode glass cell of capacity $100 \mathrm{ml}$. 
Three different types of electrodes were used; saturated calomel electrode (SCE) and a platinum foil were used as reference and auxiliary electrodes, respectively. The working electrode was in the form of a square cut from Al$\mathrm{Si}$ alloy sheet under investigation and was embedded in a Teflon rod with an exposed area of $1 \mathrm{~cm}^{2}$. This electrode was immersed in $100 \mathrm{ml}$ of a test solution into the polarization cell. A time interval of about $30 \mathrm{~min}$ was given for the system to attain a steady state [open-circuit potential $\left.\left(E_{\text {ocp }}\right)\right]$. All the experiments were carried out at $25 \pm 1{ }^{\circ} \mathrm{C}$ using an ultra-circulating thermostat. The potentiodynamic current potential curves were recorded by changing the electrode potential automatically from -0.5 to $1.5 \mathrm{mV}$ versus open-circuit potential $\left(E_{\text {ocp }}\right)$ with a scan rate of $1 \mathrm{mV} / \mathrm{s}$.

\subsubsection{Electrochemical Impedance Spectroscopy (EIS) Technique}

The cell and the apparatus used in electrochemical impedance spectroscopy (EIS) technique are the same as used in potentiodynamic polarization technique. EIS experiments were conducted over a frequency range of $10 \mathrm{kHz}$ to $100 \mathrm{~m} \mathrm{~Hz}$, with a signal amplitude perturbation of $5 \mathrm{mV}$. All impedance data were fitted to an appropriate equivalent circuit. All the potentials reported are referred to SCE. The impedance diagrams are given in the Nyquist and Bode representations.

\subsubsection{Electrochemical Frequency Modulation (EFM) Technique}

Electrochemical frequency modulation was carried out using two frequencies 2 and $5 \mathrm{~Hz}$. The base frequency was $0.1 \mathrm{~Hz}$, so the waveform repeats after $1 \mathrm{~s}$. The larger peaks were used to calculate the corrosion current density $\left(i_{\text {corr }}\right)$, the tafel slopes $\left(\beta_{\mathrm{c}}\right.$ and $\left.\beta_{\mathrm{a}}\right)$, and the causality factors CF2 and CF3. The electrode potential was allowed to stabilize for $30 \mathrm{~min}$ before starting the measurements.

All the experiments were carried out at $25 \pm 1{ }^{\circ} \mathrm{C}$ using ultra-circulating thermostat. Measurements were performed using Gamry instrument PCI4G750 Potentiostat/ Galvanostat/ZRA. This includes a Gamry framework system based on the ESA 400. Gamry applications include DC105 for DC corrosion, EIS300 for EIS, and EFM140 for EFM measurements along with a computer for collecting data. Echem Analyst 5.58 software was used for plotting, graphing, and fitting data.

\subsection{Hydrogen Evolution Determination}

The apparatus and procedure used for hydrogen evolution method was similar to that described in literature [26-35].
The gasometric assembly measures the volume of hydrogen gas evolution from the reaction system. Six Al-Si alloy coupons of dimension $2 \mathrm{~cm} \times 2 \mathrm{~cm} \times 0.05 \mathrm{~cm}$ were used in the experiments for test solutions containing $1 \mathrm{M} \mathrm{HCl}$ with the five different concentrations of investigated inhibitors from $1 \times 10^{-6} \mathrm{M}$ to $20 \times 10^{-6} \mathrm{M}$ and the blank at $30{ }^{\circ} \mathrm{C}$. A $50 \mathrm{ml}$ of each test solution was introduced into the reaction vessel connected to a burette through a delivery tube. The initial volume of air in the burette was recorded. Thereafter, one Al-Si alloy coupon was dropped into the corroded solution and the reaction vessel quickly closed. Variation in the volume of hydrogen gas evolved with time was recorded every $1 \mathrm{~min}$. for $60 \mathrm{~min}$. Each experiment was conducted on a fresh specimen of alloy coupon.

\section{Results and Discussion}

\subsection{Potentiodynamic Polarization Measurements}

Polarization measurements were carried out to obtain Tafel plots in the absence and presence of various concentrations of the investigated inhibitors. The current-potential relationship for the Al-Si alloy electrode at different test solutions of compound (1) [as the most effective inhibitor] is shown in Fig. 1; similar curves were obtained for the other compounds (not shown). The corrosion kinetic parameters such as corrosion current density $\left(i_{\text {corr }}\right)$, corrosion potential $\left(E_{\text {corr }}\right)$, the anodic Tafel slopes $\left(\beta_{\mathrm{a}}\right)$, cathodic Tafel slope $\left(\beta_{\mathrm{c}}\right)$, degree of surface coverage $(\theta)$, and the inhibition efficiency $(\% \eta)$ for the aluminum in $1 \mathrm{M} \mathrm{HCl}$ solution in the absence and presence of different concentrations of all inhibitors are listed in Table 2. The results of this Table indicated that the corrosion current density $\left(i_{\text {corr }}\right)$ decreases in the presence of inhibitors compared to the

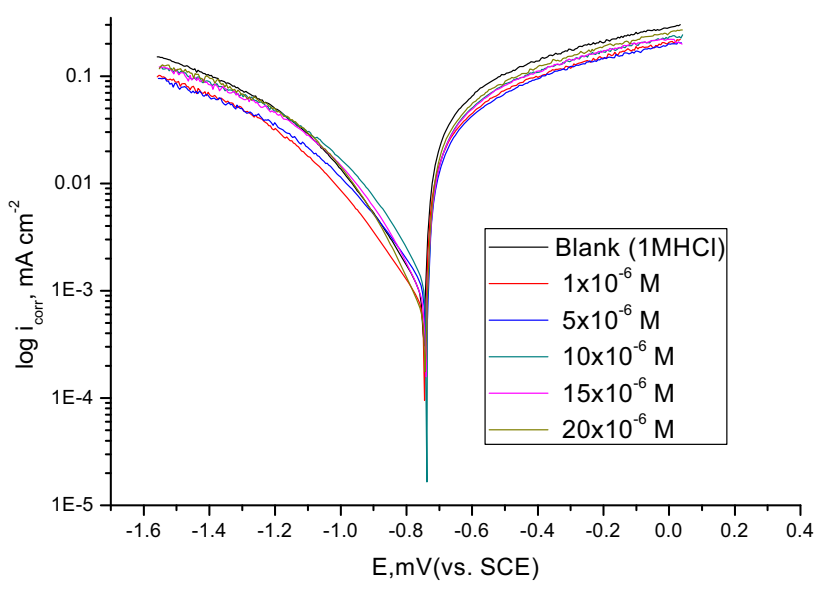

Fig. 1 Potentiodynamic polarization curve for the dissolution of Al$\mathrm{Si}$ alloy in $1 \mathrm{M} \mathrm{HCl}$ in the absence and presence of different concentrations of compound (1) at $25^{\circ} \mathrm{C}$ 
Table 2 Electrochemical kinetic parameters obtained from potentiodynamic polarization technique for the dissolution of Al-Si alloy in $1 \mathrm{M}$ $\mathrm{HCl}$ at different concentrations of investigated inhibitors at $25{ }^{\circ} \mathrm{C}$

\begin{tabular}{|c|c|c|c|c|c|c|c|c|}
\hline Comp. & Conc. $\times 10^{6} \mathrm{M}$ & $-E_{\text {corr }} \mathrm{mV}$ versus $\mathrm{SCE}$ & $i_{\text {corr }} \mathrm{mA} \mathrm{cm}^{-2}$ & $\beta_{\mathrm{c}} \mathrm{mV} \mathrm{\textrm {dec } ^ { - 1 }}$ & $\beta_{\mathrm{a}} \mathrm{mV} \mathrm{\textrm {dec } ^ { - 1 }}$ & $\theta$ & $\% \eta$ & $\overline{\mathrm{CR} \mathrm{mm} \mathrm{y}}{ }^{-1}$ \\
\hline Blank & 1 & 880 & 690.1 & 469 & 638 & - & - & 581.3 \\
\hline \multirow[t]{5}{*}{1} & 1 & 267 & 95.9 & 945 & 120 & 0.861 & 86.1 & 230.7 \\
\hline & 5 & 242 & 84.7 & 174 & 345 & 0.877 & 87.7 & 226.9 \\
\hline & 10 & 271 & 70 & 210 & 311 & 0.898 & 89.8 & 219.4 \\
\hline & 15 & 251 & 53.5 & 164 & 287 & 0.922 & 92.2 & 204.5 \\
\hline & 20 & 280 & 40.3 & 214 & 587 & 0.941 & 94.1 & 198.3 \\
\hline \multirow[t]{5}{*}{2} & 1 & 326 & 183.2 & 145 & 621 & 0.734 & 73.4 & 298.4 \\
\hline & 5 & 340 & 149.4 & 132 & 274 & 0.783 & 78.3 & 274.2 \\
\hline & 10 & 333 & 131.5 & 523 & 3.46 & 0.809 & 80.9 & 261.3 \\
\hline & 15 & 361 & 108.7 & 684 & 241 & 0.844 & 84.4 & 245.5 \\
\hline & 20 & 346 & 98.7 & 141 & 322 & 0.857 & 85.7 & 238.4 \\
\hline \multirow[t]{5}{*}{3} & 1 & 549 & 300.4 & 213 & 4.28 & 0.564 & 56.4 & 370.1 \\
\hline & 5 & 523 & 282.5 & 462 & 142 & 0.591 & 59.1 & 352.8 \\
\hline & 10 & 536 & 253.2 & 326 & 2.21 & 0.637 & 63.3 & 336.7 \\
\hline & 15 & 541 & 232.7 & 895 & 348 & 0.662 & 66.2 & 323.6 \\
\hline & 20 & 512 & 190.9 & 564 & 121 & 0.722 & 72.2 & 307.5 \\
\hline \multirow[t]{5}{*}{4} & 1 & 651 & 406.8 & 256 & 645 & 0.411 & 41.1 & 446.8 \\
\hline & 5 & 653 & 390.4 & 357 & 254 & 0.434 & 43.4 & 432.1 \\
\hline & 10 & 655 & 371.6 & 287 & 192 & 0.461 & 46.1 & 426.9 \\
\hline & 15 & 641 & 350.2 & 528 & 654 & 0.492 & 49.2 & 402.4 \\
\hline & 20 & 635.1 & 334.1 & 50.3 & 74.2 & 0.516 & 51.6 & 394.3 \\
\hline \multirow[t]{5}{*}{5} & 1 & 760 & 501.3 & 53.3 & 2.75 & 0.273 & 27.3 & 468.9 \\
\hline & 5 & 761.2 & 490.5 & 3.67 & 1.82 & 0.289 & 28.9 & 456.8 \\
\hline & 10 & 756 & 445.6 & 2.17 & 1.7 & 0.354 & 35.4 & 431.4 \\
\hline & 15 & 725.4 & 430.2 & 62.3 & 71.7 & 0.377 & 37.7 & 425.7 \\
\hline & 20 & 730.1 & 412.1 & 48.6 & 101.3 & 0.403 & 40.3 & 402.5 \\
\hline
\end{tabular}

blank solution and also with increasing the inhibitor concentrations, which suggest that the presence of these compounds retards the dissolution of aluminum in $1 \mathrm{M}$ $\mathrm{HCl}$ solution. Presence of these inhibitors cause decrease in the corrosion rate, so shift both the anodic and cathodic curves to lower values of current densities. This implies that both the hydrogen evolution and the anodic dissolution of Al/Si alloy are inhibited. This is due to adsorption of the inhibitors on the corroding surface [36, 37]. The slopes of the anodic and cathodic Tafel lines $\left(\beta_{\mathrm{a}}, \beta_{\mathrm{c}}\right)$ were slightly changed on increasing the concentration of the investigated compounds. This means that there is no change of the mechanism of the inhibition in presence and absence of inhibitors and those inhibitors affects both anodic and cathodic reactions [38], i.e., it is mixed-type inhibitors. Inhibition efficiency $(\% \eta)$ and degree of surface coverage $(\theta)$ were calculated using the following equation:

$\% \eta=\theta \times 100=\left[1-\left(i_{\text {corr }} / i_{\text {corr }}^{\circ}\right)\right] \times 100$

where $\left(i_{\text {corr }}\right.$ and $\left.i_{\text {corr }}^{\circ}\right)$ are the corrosion current densities in the presence and absence of inhibitors, respectively. The order of $\% \eta$ was found to decrease in the following sequence: $(1)>(2)>(3)>(4)>(5)$.

\subsection{Electrochemical Impedance Spectroscopy (EIS) Measurements}

EIS measurements were carried out at $25^{\circ} \mathrm{C}$ in acid solution with and without inhibitors. A typical example of EIS data obtained for compound (1) [as the most effective inhibitor] is represented as Nyquist and Bode plots in Fig. $2 \mathrm{a}$ and b. Similar curves were obtained for other compounds (not shown). The complex impedance diagram is characterized by a single full semicircular appearance indicating that corrosion of Al-Si alloy is controlled by a charge transfer process [39]. Small distortion was observed in the diagrams, this distortion has been attributed to frequency dispersion [40]. The obtained diameters of the capacitive loops increase in the presence of inhibitors and are indicative of the extent of inhibition of corrosion process, contrary to the decrease of the capacity of double layer $\left(C_{\mathrm{dl}}\right)$ which is defined as: 
Fig. 2 a Nyquist plots for the corrosion of Al-Si alloy in $1 \mathrm{M}$ $\mathrm{HCl}$ in the absence and presence of different concentrations of compound (1) at $25{ }^{\circ} \mathrm{C}$. b The bode plots for $\mathrm{Al}-\mathrm{Si}$ alloy in $1 \mathrm{M} \mathrm{HCl}$ solution in the absence and presence of different concentrations of compound (1) at $25{ }^{\circ} \mathrm{C}$
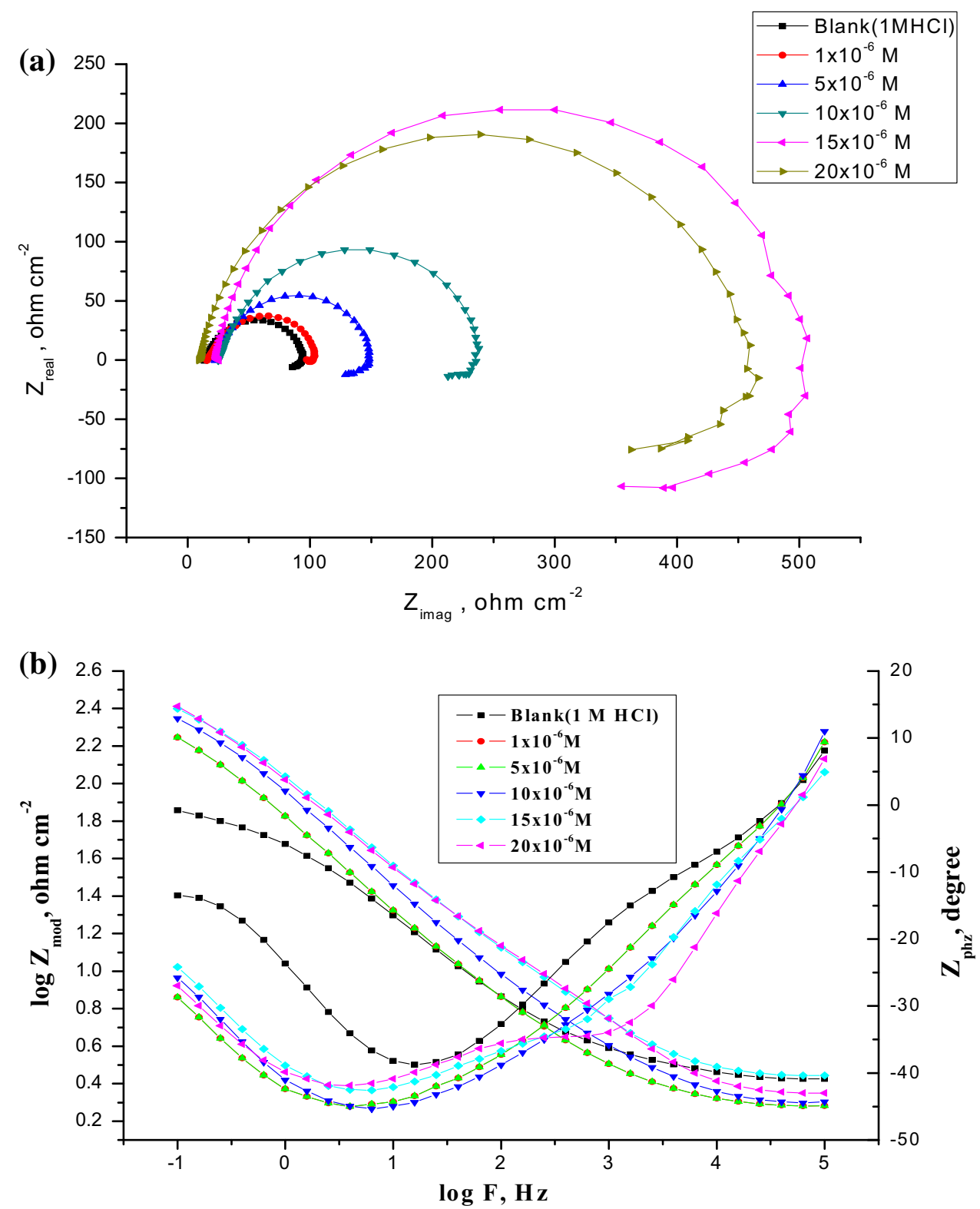

$C_{\mathrm{dl}}=\left(2 \pi f_{\max } R_{\mathrm{ct}}\right)^{-1}$

The inhibition efficiencies obtained from the EIS measurements are calculated from the relation:

$\% \eta=\theta \times 100=\left[1-\left(R_{\mathrm{ct}}^{\circ} / R_{\mathrm{ct}}\right)\right] \times 100$,

where $\left(R_{\mathrm{ct}}^{\circ}\right.$ and $\left.R_{\mathrm{ct}}\right)$ are the transfer resistance for the uninhibited and inhibited solutions, respectively. The analysis of the EIS parameters shows that $R_{\mathrm{ct}}$ increases by increasing the concentration of inhibitors, giving consequently a decrease in the corrosion rate. It is important to emphasize that the values of $C_{\mathrm{dl}}$ decrease with increasing the inhibitor concentration. This is due to the gradual replacement of water molecules in the double layer by the adsorbed inhibitor molecules which form an adherent film on the metal surface and leads to decrease in the local dielectric constant of the metal solution interface [41]. The high frequency limits corresponds to $\left(R_{\mathrm{ct}}+R_{\mathrm{s}}\right)$. The low frequency contribution shows the kinetic response of charge transfer reaction [42]. EIS data are shown in Table 3, from this Table, it is clear that the inhibition efficiency $(\% \eta)$ of these compounds follows the same sequence as before: $(1)>(2)>(3)>$ (4) $>$ (5) . 
Table 3 Electrochemical kinetic parameters obtained from EIS technique for the corrosion of Al-Si alloy in $1 \mathrm{M}$ $\mathrm{HCl}$ at different concentrations of investigated inhibitors at $25{ }^{\circ} \mathrm{C}$

\begin{tabular}{|c|c|c|c|c|c|}
\hline Comp. & Conc. $\times 10^{6} \mathrm{M}$ & $C_{\mathrm{dl}} \times 10^{-3}, \mu \mathrm{F} \mathrm{cm}^{-2}$ & $R_{\mathrm{ct}}, \Omega \mathrm{cm}^{2}$ & $\theta$ & $\% \eta$ \\
\hline Blank & 0 & 14 & 10.8 & - & - \\
\hline \multirow[t]{5}{*}{1} & 1 & 1.99 & 263.5 & 0.959 & 95.9 \\
\hline & 5 & 2.56 & 315.8 & 0.965 & 96.5 \\
\hline & 10 & 1.14 & 352.3 & 0.969 & 96.9 \\
\hline & 15 & 1.2 & 403.9 & 0.973 & 97.3 \\
\hline & 20 & 1.54 & 450.1 & 0.976 & 97.6 \\
\hline \multirow[t]{5}{*}{2} & 1 & 3 & 221.1 & 0.906 & 90.6 \\
\hline & 5 & 2.87 & 288.7 & 0.913 & 91.3 \\
\hline & 10 & 2.69 & 316.8 & 0.922 & 92.2 \\
\hline & 15 & 1.9 & 347.3 & 0.926 & 92.6 \\
\hline & 20 & 2.41 & 359.4 & 0.932 & 93.2 \\
\hline \multirow[t]{5}{*}{3} & 1 & 9.3 & 168.9 & 0.816 & 81.6 \\
\hline & 5 & 7.6 & 171.3 & 0.848 & 84.8 \\
\hline & 10 & 7.4 & 282.4 & 0.869 & 86.9 \\
\hline & 15 & 6.9 & 291.1 & 0.881 & 88.1 \\
\hline & 20 & 5.32 & 297.5 & 0.889 & 88.9 \\
\hline \multirow[t]{5}{*}{4} & 1 & 1.99 & 119.2 & 0.66 & 66 \\
\hline & 5 & 1.96 & 130.8 & 0.735 & 73.5 \\
\hline & 10 & 1.7 & 147.3 & 0.773 & 77.3 \\
\hline & 15 & 2.35 & 152.9 & 0.787 & 78.7 \\
\hline & 20 & 1.2 & 178.1 & 0.802 & 80.2 \\
\hline \multirow[t]{5}{*}{5} & 1 & 3 & 74.7 & 0.414 & 41.4 \\
\hline & 5 & 2.8 & 81.3 & 0.443 & 44.3 \\
\hline & 10 & 2.4 & 89.1 & 0.497 & 49.7 \\
\hline & 15 & 5.14 & 94.2 & 0.546 & 54.6 \\
\hline & 20 & 1.9 & 98.8 & 0.559 & 55.9 \\
\hline
\end{tabular}

\subsection{Electrochemical Frequency Modulation (EFM) Measurements}

The EFM is a nondestructive corrosion measurement technique that can directly give values of the corrosion current without prior knowledge of Tafel constants. It is generally accepted that in most cases, the corrosion rates determined with the EFM technique are much higher than the values determined with other techniques exhibiting low corrosion rates [43]. Intermodulation spectra obtained from EFM measurements are presented in Fig. $3 a$ and $b$ for examples of $\mathrm{Al}-\mathrm{Si}$ alloy in corroded $1 \mathrm{M} \mathrm{HCl}$ solutions devoid of and containing $20 \times 10^{-6} \mathrm{M}$ of compound (I) [as the most effective inhibitor] at $25{ }^{\circ} \mathrm{C}$. Similar intermodulation spectra were obtained for other compounds (not shown). Each spectrum is a current response as a function of frequency. The calculated corrosion kinetic parameters at different concentrations of the investigated compounds in $1 \mathrm{M} \mathrm{HCl}$ at $25^{\circ} \mathrm{C}\left(i_{\text {corr }}, \beta_{\mathrm{a}}, \beta_{\mathrm{c}}, \mathrm{CF}-2, \mathrm{CF}-3\right.$, and $\% \eta$ ) are given in Table 4. From Table 4, the corrosion current densities decreased by increasing the concentration of investigated compounds and hence, the inhibition efficiencies increased. The causality factors in Table 4 are very close to theoretical values which according to EFM theory [44] should guarantee the validity of Tafel slopes and corrosion current densities. Values of causality factors in Table 4 indicate that the measured data are of good quality. The standard values for CF-2 and CF-3 are 2.0 and 3.0, respectively. The deviation of causality factors from their ideal values might due to that the perturbation amplitude was too small or that the resolution of the frequency spectrum is not high enough also another possible explanation that the inhibitor is not performing very well. The obtained results showed good agreement of corrosion kinetic parameters obtained with the EIS and Tafel polarization measurements.

\subsection{Adsorption Isotherms}

One possible mechanism for corrosion inhibition using organic compounds is the adsorption of the inhibitor which blocks the metal surface and thus do not permit the corrosion to take place. The adsorption provides the information about the interaction among the adsorbed molecules 

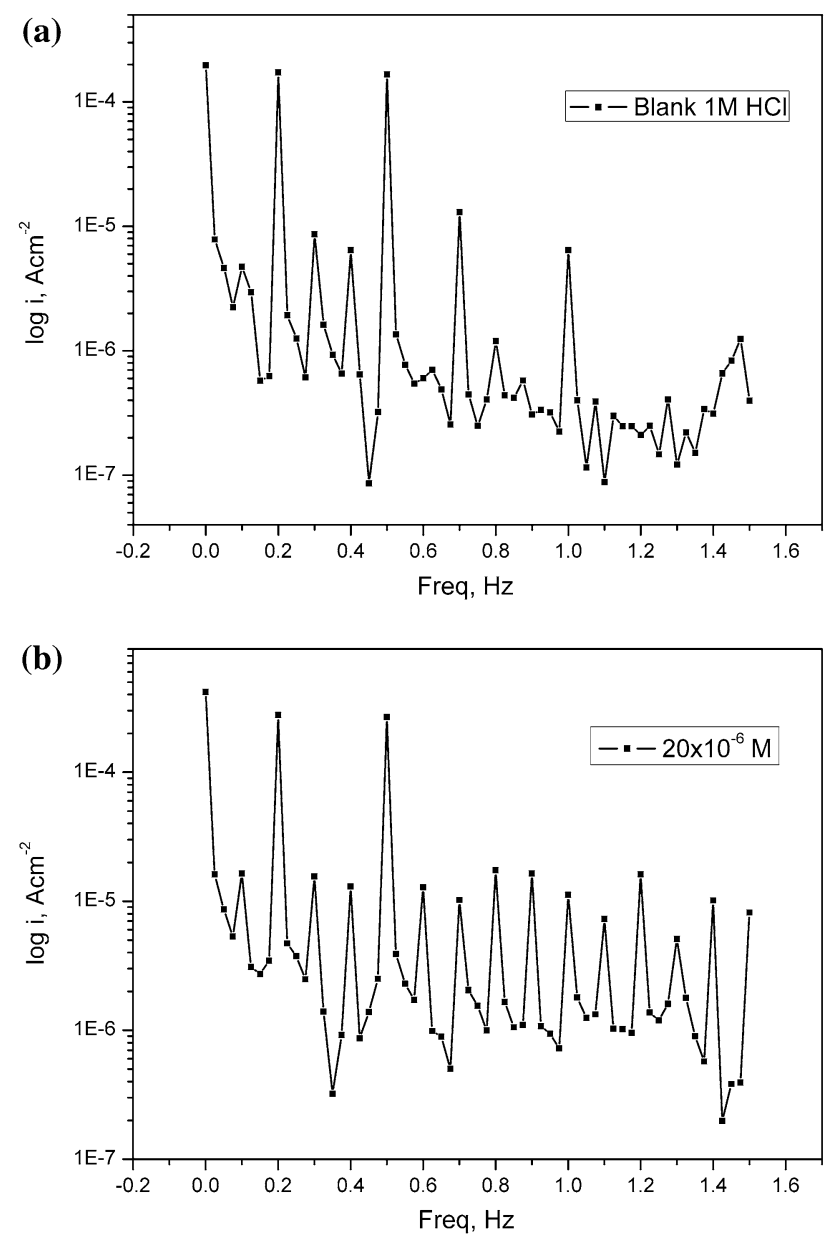

Fig. 3 a EFM spectra for $\mathrm{Al}-\mathrm{Si}$ alloy $1 \mathrm{M} \mathrm{HCl}$ (blank) and b EFM spectra for Al-Si alloy in $1 \mathrm{M} \mathrm{HCl}$ in the presence of $20 \times 10^{-6} \mathrm{M}$ inhibitor (1)

themselves as well as their interaction with the metal surface [45]. Two main types of interaction can describe the adsorption of organic compounds namely: physical adsorption and chemical adsorption. These are dependent on the electronic structure of the metal, the nature of the electrolyte, and the chemical structure of the inhibitor. Adsorption isotherms are very important to understand the mechanism of heterogeneous organo-electrochemical reactions [46] involving solid surfaces. It was found that the best suitable adsorption isotherm for the studied inhibitors on the aluminum alloy surface is the Langmuir equation [47] which was defined as follows:

$C / \theta=1 / K_{\mathrm{ads}}+C$

where $K_{\text {ads }}$ is equilibrium constant of adsorption process and $C$ is concentration of inhibitor. The plots of $C / \theta$ versus $C$ for compound (1) [as the most effective inhibitor] at different temperatures are shown in Fig. 4. These plots are linear with slope and correlation coefficients $\left(R^{2}\right)$ near to unity. Similar curves were obtained for the other compounds (not shown). The thermodynamic adsorption parameters were calculated. The well-known thermodynamic adsorption parameters are the standard free energy of adsorption $\left(\Delta G_{\mathrm{ads}}^{\circ}\right)$, the heat of adsorption $\left(\Delta H_{\mathrm{ads}}^{\circ}\right)$, and the entropy of adsorption $\left(\Delta S_{\mathrm{ads}}^{\circ}\right)$. These quantities can be calculated by various mathematical methods depending on the values of $K_{\text {ads }}$ from adsorption isotherms at different temperatures [48]. The $\Delta G_{\mathrm{ads}}^{\circ}$ can be calculated from Eq. 5:

$K_{\text {ads }}=(1 / 55.5) \exp \left(-\Delta G_{\text {ads }}^{\circ} / R T\right)$

where 55.5 is the concentration of water in $\mathrm{mol} \mathrm{l}^{-1}$. The heat of adsorption $\left(\Delta H_{\mathrm{ads}}^{\circ}\right)$ could be calculated according to the Van't Hoff equation:

$\log K_{\text {ads }}=\left(-\Delta H_{\text {ads }}^{\circ} / 2.303 R T\right)+$ constant

In order to calculate the heat of adsorption $\left(\Delta H_{\mathrm{ads}}^{\circ}\right)$, (log $\left.K_{\text {ads }}\right)$ was plotted against $(1 / T)$ as shown in Fig. 5. The straight lines were obtained with slope equal to $\left(-\Delta H_{\mathrm{ads}}^{\circ} /\right.$ $\mathrm{R})$. Then in accordance with the basic equation:

$\Delta G_{\text {ads }}^{\circ}=\Delta H_{\text {ads }}^{\circ}-T \Delta S_{\text {ads }}^{\circ}$

By introducing the obtained $\Delta G_{\text {ads }}^{\circ}$ and $\Delta H_{\text {ads }}^{\circ}$ values in Eq. 7 , the entropy of adsorption $\left(\Delta S_{\text {ads }}^{\circ}\right)$ values were calculated at all studied temperatures. Table 5 shows all the estimated thermodynamic adsorption parameters for the investigated derivatives on aluminum alloy surface and concluded that: Large values of $K_{\text {ads }}$ mean good inhibition efficiency of the investigated derivatives strong electrical interaction between the adsorbate and the adsorbent. The sign of $\Delta G_{\text {ads }}^{\circ}$ was negative which reflects that the adsorption of these compounds on Al-Si alloy surface is spontaneous process. It is well known that values of $\Delta G_{\text {ads }}^{\circ}$ of the order of $40 \mathrm{~kJ} \mathrm{~mol}^{-1}$ or higher involve charge sharing or transfer from the inhibitor molecules to metal surface to form coordinate type of bond (chemisorptions); those of order of $20 \mathrm{~kJ} \mathrm{~mol}^{-1}$ or lower mean that the electrostatic interaction between metal surface and charged organic molecules in the bulk of the solution indicates a physisorption $[49,50]$. The calculated $\Delta G_{\text {ads }}^{\circ}$ values are between 25 and $22 \mathrm{~kJ} \mathrm{~mol}^{-1}$ which indicate that the adsorption mechanism of the investigated compounds on $\mathrm{Al}-\mathrm{Si}$ alloy in $1 \mathrm{M} \mathrm{HCl}$ solution is physisorption, so it is a comprehensive adsorption (physical and chemical). The negative sign of $\Delta H_{\mathrm{ads}}^{\circ}$ indicates that the adsorption process of inhibitor molecules is an exothermic process. Generally, an exothermic adsorption process suggests either physisorption or chemisorptions, while endothermic process is attributed to chemisorptions [51]. Generally, the enthalpies values up to $41.9 \mathrm{~kJ} \mathrm{~mol}^{-1}$ are related to physisorption, while those around $100 \mathrm{~kJ} \mathrm{~mol}^{-1}$ or higher are attributed to chemisorptions. The unshared electron 
Table 4 Electrochemical kinetic parameters obtained from EFM technique for $\mathrm{Al}-\mathrm{Si}$ alloy in $1 \mathrm{M} \mathrm{HCl}$ in the absence and presence of different concentrations of investigated inhibitors

\begin{tabular}{|c|c|c|c|c|c|c|c|}
\hline Comp. & Conc. $\times 10^{6}, \mathrm{M}$ & $i_{\text {corr }}, \mu \mathrm{A} \mathrm{cm}{ }^{2}$ & $\beta_{\mathrm{a}}, \mathrm{mV} \mathrm{dec}{ }^{-1}$ & $\beta_{\mathrm{c},}, \mathrm{mV} \mathrm{dec}{ }^{-1}$ & CF-2 & CF-3 & $\% \eta$ \\
\hline Blank & 0 & 782.3 & 225.9 & 307.6 & 1.97 & 4.98 & - \\
\hline \multirow[t]{5}{*}{1} & 1 & 276.1 & 213.7 & 245.9 & 2.53 & 1.32 & 64.7 \\
\hline & 5 & 259.8 & 180.4 & 221.7 & 2.96 & 2.78 & 66.8 \\
\hline & 10 & 177.9 & 167.6 & 213.6 & 1.67 & 3.21 & 77.2 \\
\hline & 15 & 135.4 & 32.95 & 53.08 & 1.89 & 6.31 & 82.6 \\
\hline & 20 & 68.6 & 83.75 & 102.1 & 1.3 & 2.06 & 91.2 \\
\hline \multirow[t]{5}{*}{2} & 1 & 310.9 & 36.16 & 49.51 & 1.46 & 2.49 & 60.2 \\
\hline & 5 & 263.7 & 25.86 & 36.21 & 2.39 & 3.37 & 66.3 \\
\hline & 10 & 252.1 & 27.44 & 28.78 & 1.19 & 3.38 & 67.8 \\
\hline & 15 & 231.8 & 31.54 & 40.85 & 1.29 & 2.56 & 70.3 \\
\hline & 20 & 206.1 & 24.65 & 30.95 & 1.95 & 2.29 & 73.6 \\
\hline \multirow[t]{5}{*}{3} & 1 & 325.5 & 45.03 & 56.55 & 1.49 & 1.56 & 58.4 \\
\hline & 5 & 312.8 & 36.99 & 38.98 & 91.3 & 1.81 & 60.2 \\
\hline & 10 & 269.3 & 18.85 & 22.48 & 98.4 & 2.85 & 65.6 \\
\hline & 15 & 242.9 & 20.18 & 35.41 & 1.36 & 3.48 & 68.9 \\
\hline & 20 & 221.1 & 30.25 & 24.58 & 3.65 & 1.27 & 71.7 \\
\hline \multirow[t]{5}{*}{4} & 1 & 411.5 & 52.24 & 55.74 & 1.31 & 1.39 & 47.4 \\
\hline & 5 & 390.9 & 99.23 & 173.2 & 1.68 & 2.11 & 50.1 \\
\hline & 10 & 368.9 & 45.57 & 49.02 & 1.27 & 1.52 & 52.8 \\
\hline & 15 & 298.2 & 35.54 & 36.16 & 51.2 & 2.01 & 61.9 \\
\hline & 20 & 270.2 & 28.93 & 34.19 & 1.82 & 3.17 & 65.5 \\
\hline \multirow[t]{5}{*}{5} & 1 & 577.1 & 234.7 & 250.9 & 1.82 & 3.45 & 26.6 \\
\hline & 5 & 545.8 & 224.3 & 257.5 & 1.97 & 12.3 & 30.3 \\
\hline & 10 & 521.1 & 111.9 & 240.8 & 1.95 & 1.06 & 33.4 \\
\hline & 15 & 503.7 & 183.9 & 242.3 & 1.75 & 2.23 & 35.7 \\
\hline & 20 & 485.6 & 195.9 & 253.8 & 1.87 & 3.59 & 37.9 \\
\hline
\end{tabular}

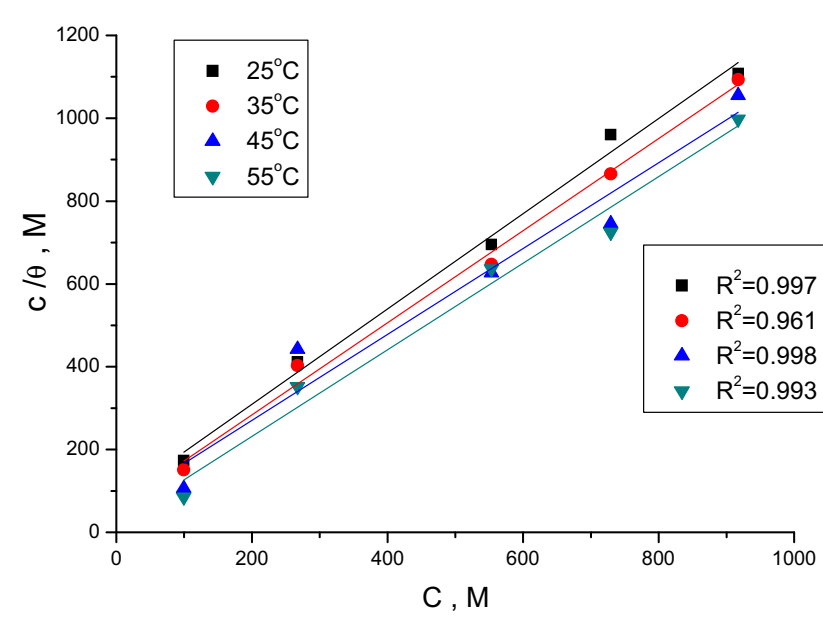

Fig. 4 Langmuir adsorption isotherm of compound (1) on $\mathrm{Al}-\mathrm{Si}$ surface in $1 \mathrm{M} \mathrm{HCl}$ at different temperatures

pairs in investigated molecules may interact with p-orbital of aluminum to provide chemisorbed film. The values of $\Delta S_{\text {ads }}^{\circ}$ are large and negative that is accompanied with exothermic adsorption process.

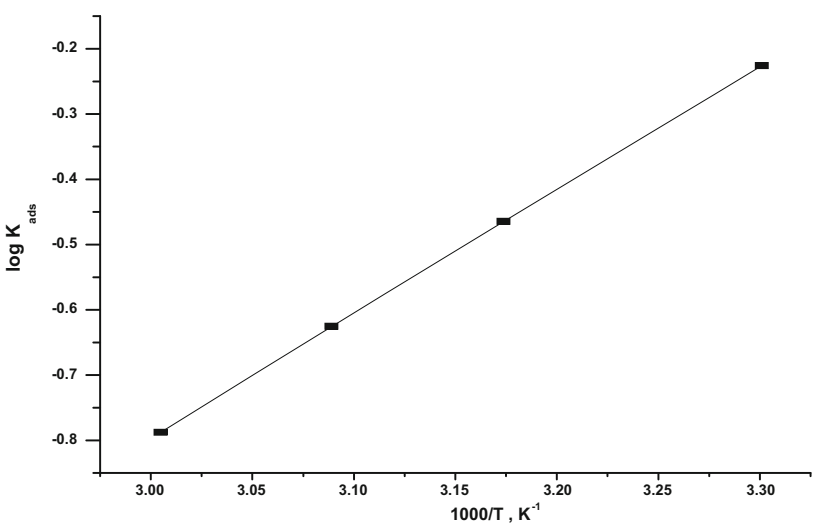

Fig. $5\left(\log K_{\text {ads }}\right)$ versus $(1 / T)$ for the corrosion of Al-Si alloy in $1 \mathrm{M}$ $\mathrm{HCl}$ in the presence of compound (1) at different temperatures

\subsection{Effect of Temperature}

The influence of temperature on the corrosion rate of $\mathrm{Al}-\mathrm{Si}$ alloy in $1 \mathrm{M} \mathrm{HCl}$ in absence and presence of different concentrations of the investigated compounds was investigated by the electrochemical frequency modulation 
Table 5 Thermodynamic adsorption parameters for the investigated compounds on Al$\mathrm{Si}$ alloy surface in $1 \mathrm{M} \mathrm{HCl}$ at different temperatures

\begin{tabular}{|c|c|c|c|c|c|}
\hline Comp. & Temp. ${ }^{\circ} \mathrm{C}$ & $K_{\text {ads }} \mathrm{M}^{-1}$ & $-\Delta G_{\mathrm{ads}}^{\circ} \mathrm{kJ} \mathrm{mol}^{-1}$ & $-\Delta H_{\mathrm{ads}}^{\circ} \mathrm{kJ} \mathrm{mol}^{-1}$ & $-\Delta S_{\mathrm{ads}}^{\circ} \mathrm{J} \mathrm{mol}^{-1} \mathrm{~K}^{-1}$ \\
\hline \multirow[t]{4}{*}{1} & 25 & 259.3 & 23.7 & \multirow[t]{4}{*}{70.3} & 56.7 \\
\hline & 35 & 248.1 & 24.4 & & 55.4 \\
\hline & 45 & 235.8 & 25.5 & & 49.6 \\
\hline & 55 & 219.7 & 21.1 & & 44.2 \\
\hline \multirow[t]{4}{*}{2} & 25 & 227.7 & 23.4 & \multirow[t]{4}{*}{62.7} & 41.9 \\
\hline & 35 & 221 & 24.1 & & 35.8 \\
\hline & 45 & 198.1 & 24.6 & & 33.9 \\
\hline & 55 & 184.3 & 25.2 & & 31.4 \\
\hline \multirow[t]{4}{*}{3} & 25 & 198.5 & 23 & \multirow[t]{4}{*}{41.9} & 25.7 \\
\hline & 35 & 191.1 & 23.7 & & 23.4 \\
\hline & 45 & 153.4 & 23.9 & & 20.6 \\
\hline & 55 & 166.7 & 24.9 & & 18.9 \\
\hline \multirow[t]{4}{*}{4} & 25 & 164.2 & 22.6 & \multirow[t]{4}{*}{36.1} & 22.4 \\
\hline & 35 & 152.8 & 23.1 & & 20.6 \\
\hline & 45 & 134.7 & 23.6 & & 19.1 \\
\hline & 55 & 147.3 & 24.6 & & 16.2 \\
\hline \multirow[t]{4}{*}{5} & 25 & 137.4 & 24.7 & \multirow[t]{4}{*}{22.9} & 19.8 \\
\hline & 35 & 121 & 22.5 & & 17.4 \\
\hline & 45 & 97.2 & 22.7 & & 15.3 \\
\hline & 55 & 82.9 & 23 & & 10.1 \\
\hline
\end{tabular}

Table 6 Variation of inhibition efficiencies $(\% \eta)$ and corrosion rates $\left(k_{\text {corr }}\right)$ for various concentrations of investigated inhibitors at different temperatures

\begin{tabular}{|c|c|c|c|c|c|c|c|c|c|c|c|}
\hline \multirow[t]{2}{*}{ Temp ${ }^{\circ} \mathrm{C}$} & \multirow[t]{2}{*}{ Conc. $\times 10^{6} \mathrm{M}$} & \multicolumn{2}{|c|}{ Comp. (1) } & \multicolumn{2}{|c|}{ Comp. (2) } & \multicolumn{2}{|c|}{ Comp. (3) } & \multicolumn{2}{|c|}{ Comp. (4) } & \multicolumn{2}{|c|}{ Comp. (5) } \\
\hline & & $\begin{array}{l}k_{\text {corr }} \\
\text { mpy }\end{array}$ & $\% \eta$ & $\begin{array}{l}k_{\text {corr }} \\
\text { mpy }\end{array}$ & $\% \eta$ & $\begin{array}{l}k_{\text {corr }} \\
\text { mpy }\end{array}$ & $\% \eta$ & $\begin{array}{l}k_{\text {corr }} \\
\text { mpy }\end{array}$ & $\% \eta$ & $\begin{array}{l}k_{\text {corr }} \\
\text { mpy }\end{array}$ & $\% \eta$ \\
\hline \multirow[t]{5}{*}{35} & 1 & 392.1 & 57.9 & 425.8 & 43.3 & 469.3 & 33.9 & 498.5 & 30.6 & 559.2 & 24.5 \\
\hline & 5 & 351.6 & 65.4 & 381.4 & 46.1 & 441.2 & 37.4 & 463.2 & 33.5 & 513.1 & 27.8 \\
\hline & 10 & 335.7 & 71.3 & 356.0 & 47.7 & 422.9 & 39.5 & 439.6 & 35.9 & 478.6 & 29.9 \\
\hline & 15 & 289.4 & 78.2 & 334.7 & 53.2 & 371.1 & 40.7 & 384.9 & 39.5 & 441.9 & 32.0 \\
\hline & 20 & 264.0 & 82.7 & 294.9 & 57.4 & 326.7 & 42.2 & 335.7 & 40.8 & 412.7 & 34.3 \\
\hline \multirow[t]{5}{*}{45} & 1 & 438.2 & 55.6 & 451.2 & 40.4 & 493.5 & 32.9 & 538.9 & 28.0 & 571.6 & 21.7 \\
\hline & 5 & 416.3 & 64.1 & 436.8 & 43.9 & 478.2 & 35.3 & 522.6 & 29.8 & 554.3 & 25.5 \\
\hline & 10 & 395.9 & 69.4 & 412.6 & 45.2 & 433.1 & 37.4 & 452.1 & 31.5 & 511.9 & 26.7 \\
\hline & 15 & 367.6 & 73.0 & 388.9 & 51.3 & 397.4 & 38.5 & 373.7 & 36.3 & 467.2 & 28.8 \\
\hline & 20 & 344.1 & 79.6 & 350.4 & 53.5 & 361.6 & 39.9 & 340.8 & 38.5 & 426.8 & 31.9 \\
\hline \multirow[t]{5}{*}{55} & 1 & 477.1 & 53.6 & 499.3 & 38.3 & 524.8 & 31.2 & 547.1 & 26.3 & 598.4 & 19.3 \\
\hline & 5 & 459.7 & 60.9 & 475.4 & 40.7 & 484.3 & 33.0 & 531.8 & 28.9 & 573.0 & 24.0 \\
\hline & 10 & 419.6 & 66.5 & 432.9 & 43.8 & 441.7 & 34.1 & 481.7 & 29.7 & 531.8 & 25.1 \\
\hline & 15 & 367.5 & 68.8 & 405.2 & 47.1 & 409.1 & 36.3 & 441.9 & 32.8 & 498.4 & 26.9 \\
\hline & 20 & 345.8 & 75.6 & 372.1 & 49.9 & 376.6 & 38.0 & 425.6 & 33.3 & 466.7 & 28.2 \\
\hline
\end{tabular}

technique in temperature range $\left(35-55^{\circ} \mathrm{C}\right)$. The inhibition efficiency $(\% \eta)$ for $\mathrm{Al}-\mathrm{Si}$ alloy corrosion in the presence of various concentrations of the investigated compounds and at different temperatures was obtained from Eq. 4. Table 6 illustrates the variation of $\% \eta$ and $k_{\text {corr }}$ with inhibitors concentrations at different temperatures. The obtained data revealed that the inhibition efficiency increased with increasing the inhibitor concentration, but the corrosion rate increased with increasing the temperature and consequently the inhibition efficiency decreased, indicating that adsorption of inhibitor species on alloy surface at these conditions is not merely physical or chemical adsorption but obeying a comprehensive adsorption (physical and chemical adsorption). 
Fig. 6 Arrhenius plots $\left(\log k_{\text {corr }}\right.$ vs. $1 / T$ ) for Al-Si alloy in the absence and presence of different concentrations of compound (1)
Fig. 7 Transition state plots $\left(\log k_{\text {corr }} / T\right.$ vs. $\left.1 / T\right)$ for $\mathrm{Al}-\mathrm{Si}$ alloy in the absence and presence of various concentrations of compound (1)
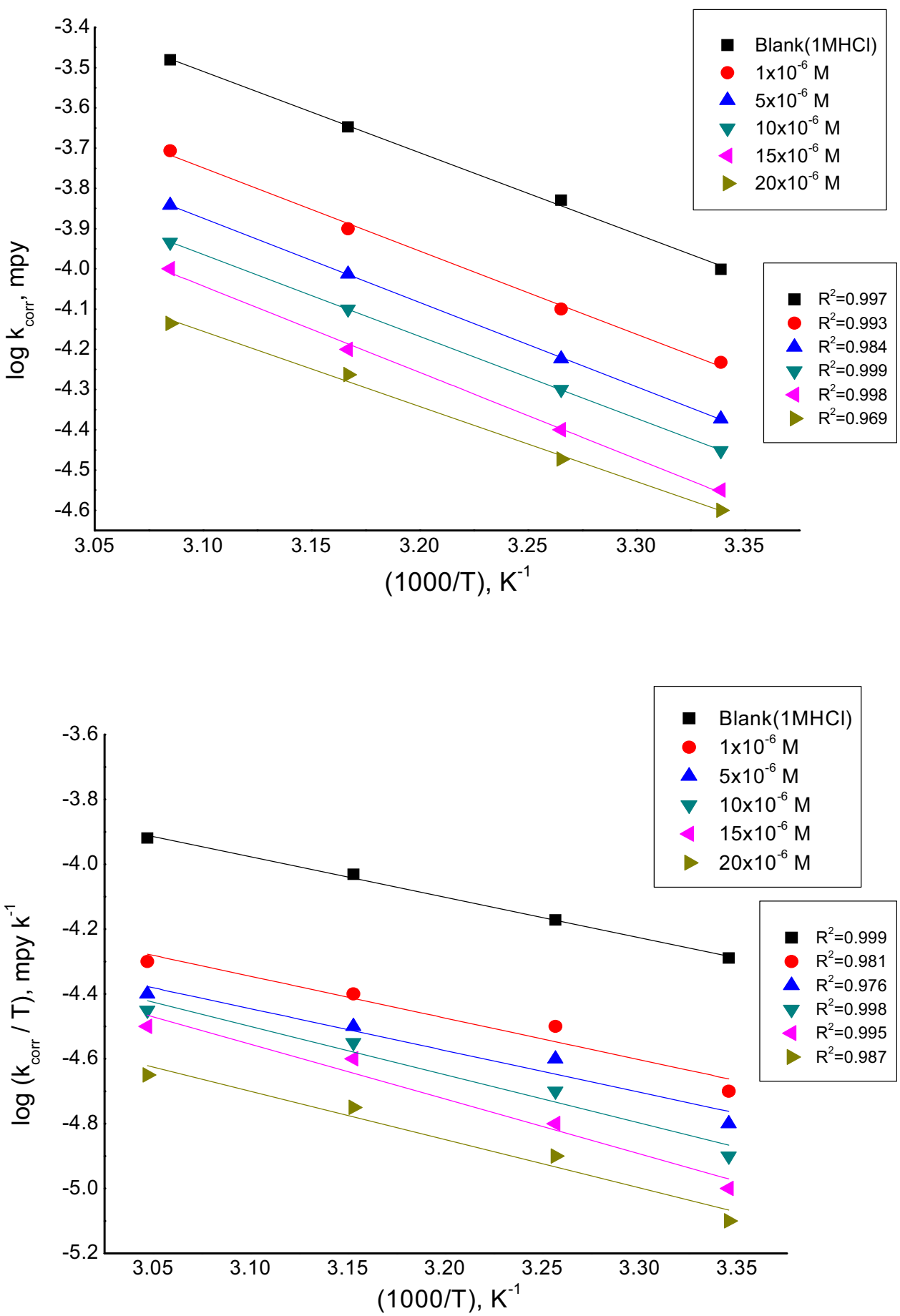

Plot of logarithm of corrosion rate (log $k_{\text {corr }}$ ), with reciprocal of absolute temperature $(1 / T)$ for Al-Si alloy in $1 \mathrm{M} \mathrm{HCl}$ at different concentrations for compound (1) [as the most effective inhibitor] is shown in Fig. 6, and similar curves were obtained for the other compounds (not shown). As shown from this Figure, straight lines with slope of $-E_{\mathrm{a}} * / 2.303 R$ and intercept of A were obtained according to Arrhenius-type equation:
$k=A \exp \left(-E_{\mathrm{a}}^{*} / R T\right)$

where $k$ is the corrosion rate, $A$ is a constant depends on a metal type and electrolyte, $E_{\mathrm{a}} *$ is the apparent activation energy, $R$ is the universal gas constant, and $T$ is the absolute temperature. Plot of $\log$ (corrosion rate/T) versus $1 / T$ for Al-Si alloy in $1 \mathrm{M} \mathrm{HCl}$ at different concentrations for compound (1) is shown in Fig. 7. As shown from this 
Table 7 Kinetic-thermodynamic parameters for Al-Si alloy corrosion in the absence and presence of various concentrations of investigated inhibitors

\begin{tabular}{|c|c|c|c|}
\hline Conc. $\mathrm{M}$ & $E_{\mathrm{a}}^{*} \mathrm{~kJ} \mathrm{~mol}^{-1}$ & $\Delta H_{\mathrm{a}}^{*} \mathrm{~kJ} \mathrm{~mol}^{-1}$ & $-\Delta S^{*} \mathrm{~J} \mathrm{~mol}^{-1} \mathrm{~K}^{-1}$ \\
\hline Blank & 29.6 & 45.4 & 112.1 \\
\hline \multicolumn{4}{|l|}{ Compound 1} \\
\hline $1 \times 10^{-6}$ & 64.8 & 61.2 & 52.7 \\
\hline $5 \times 10^{-6}$ & 69.1 & 63.4 & 43.9 \\
\hline $10 \times 10^{-6}$ & 73.4 & 64.9 & 38.3 \\
\hline $15 \times 10^{-6}$ & 79.2 & 71.5 & 24.1 \\
\hline $20 \times 10^{-6}$ & 85.7 & 72.8 & 19.2 \\
\hline \multicolumn{4}{|l|}{ Compound 2} \\
\hline $1 \times 10^{-6}$ & 56.7 & 52.5 & 58.4 \\
\hline $5 \times 10^{-6}$ & 59.5 & 54.9 & 47.2 \\
\hline $10 \times 10^{-6}$ & 63.1 & 57.7 & 41.8 \\
\hline $15 \times 10^{-6}$ & 70.4 & 65.8 & 36.3 \\
\hline $20 \times 10^{-6}$ & 75.3 & 68.1 & 32.1 \\
\hline \multicolumn{4}{|l|}{ Compound 3} \\
\hline $1 \times 10^{-6}$ & 45.1 & 41.9 & 60.7 \\
\hline $5 \times 10^{-6}$ & 48.8 & 43.4 & 52.3 \\
\hline $10 \times 10^{-6}$ & 50.3 & 48.2 & 45.1 \\
\hline $15 \times 10^{-6}$ & 58.7 & 53.7 & 43.7 \\
\hline $20 \times 10^{-6}$ & 64.9 & 57.1 & 41.5 \\
\hline \multicolumn{4}{|l|}{ Compound 4} \\
\hline $1 \times 10^{-6}$ & 42.2 & 36.6 & 65.4 \\
\hline $5 \times 10^{-6}$ & 46.5 & 38.9 & 61.9 \\
\hline $10 \times 10^{-6}$ & 48.9 & 44.3 & 54.3 \\
\hline $15 \times 10^{-6}$ & 53.4 & 50.1 & 51.2 \\
\hline $20 \times 10^{-6}$ & 60 & 55.7 & 42.1 \\
\hline \multicolumn{4}{|l|}{ Compound 5} \\
\hline $1 \times 10^{-6}$ & 38.2 & 29.4 & 71.5 \\
\hline $5 \times 10^{-6}$ & 43.1 & 33.7 & 63.1 \\
\hline $10 \times 10^{-6}$ & 47.7 & 39.5 & 57.6 \\
\hline $15 \times 10^{-6}$ & 52.3 & 46.8 & 53.7 \\
\hline $20 \times 10^{-6}$ & 59.4 & 51.6 & 44.8 \\
\hline
\end{tabular}

Figure, straight lines with slope of $\left(-\Delta H^{*} / 2.303 R\right)$ and intercept of $\left(\log R / N h+\Delta S^{*} / 2.303 R\right)$ were obtained according to transition state equation:

Rate $=R T / N h \exp \left(\Delta S^{*} / R\right) \exp \left(-\Delta H^{*} / R T\right)$

where $h$ is Planck's constant, $N$ is Avogadro's number, $\Delta H^{*}$ is the activation enthalpy, and $\Delta S^{*}$ is the activation entropy.

All estimated thermodynamic activation parameters are tabulated in Table 7. The data show that the presence of the investigated compounds increases the apparent activation energy due to the formation of energy barrier which needs higher activation energy [52, 53]. All values of $E_{\mathrm{a}}^{*}$ are larger than the analogous values of $\Delta H^{*}$ indicating that the corrosion process must involved a gaseous reaction, simply

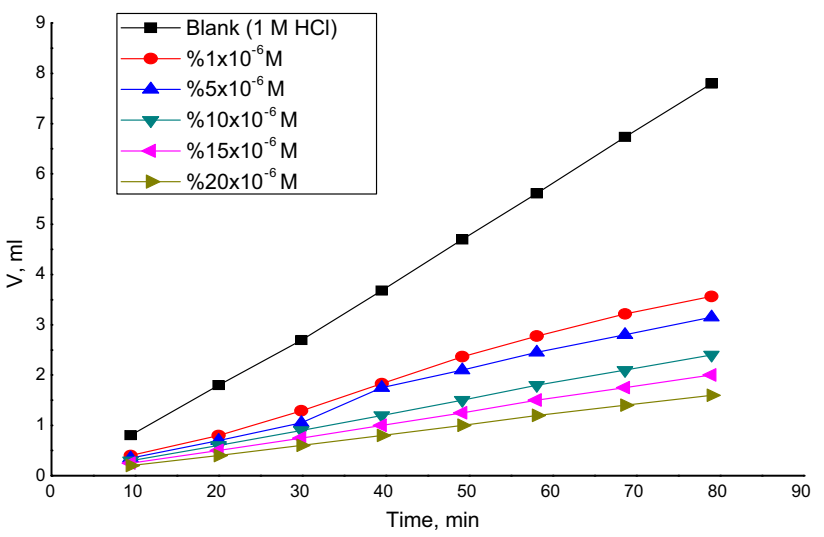

Fig. 8 Volume of hydrogen gas evolved during the dissolution of Al$\mathrm{Si}$ alloy in $1 \mathrm{M} \mathrm{HCl}$ in the absence and presence of different concentrations of compound (1) at $25{ }^{\circ} \mathrm{C}$

Table 8 Inhibition efficiency obtained from hydrogen evolution method for $\mathrm{Al}-\mathrm{Si}$ alloy in $1 \mathrm{M} \mathrm{HCl}$ at various concentrations of compound (1) at $25{ }^{\circ} \mathrm{C}$

\begin{tabular}{llc}
\hline$[$ Inh $] \times 10^{6} \mathrm{M}$ & $\begin{array}{l}\text { Volume of hydrogen } \\
\text { gas evolved }(\mathrm{ml})\end{array}$ & $\% \eta$ \\
\hline Blank & 8.1 & - \\
1 & 2.7 & 66.7 \\
5 & 2.3 & 71.6 \\
10 & 1.8 & 77.8 \\
15 & 1.5 & 81.5 \\
20 & 1.1 & 86.4 \\
\hline
\end{tabular}

the hydrogen evolution reaction [54]. The entropy of activation $\Delta S^{*}$ in the absence and presence of inhibitor has negative values which indicates that the activated complex in the rate determining step prefer association rather than dissociation, meaning that, a decrease in disordering takes place on going from reactants to the activated complex [55].

\subsection{Gasometric Measurements}

The inhibitive effect of investigated derivatives on the corrosion of $\mathrm{Al}-\mathrm{Si}$ alloy in $1 \mathrm{M} \mathrm{HCl}$ at a temperature of $25^{\circ} \mathrm{C}$ was also investigated using hydrogen evolution technique. This technique gives a rapid and sensitive means for determining any interruption by the inhibitor with regard to gas evolution at the metal-corrodent interface. Results obtained by this technique are well matching by other results obtained from other methods. Figure 8 is a typical plot showing the variation of $\mathrm{H}_{2}$ gas volume evolved with time for $1 \mathrm{M} \mathrm{HCl}$ without and with different concentrations of the inhibitors at $25^{\circ} \mathrm{C}$. The plots reveal slow rates of hydrogen evolution at the start of the reaction, 
Table 9 The calculated quantum chemical parameters for the investigated compounds

\begin{tabular}{llllll}
\hline Parameter & Comp. (1) & Comp. (2) & Comp. (3) & Comp. (4) & Comp. (5) \\
\hline$-E_{\mathrm{HOMO}}(\mathrm{eV})$ & 9.041 & 9.146 & 9.623 & 9.686 & 9.699 \\
$-E_{\mathrm{LUMO}}(\mathrm{eV})$ & 0.727 & 0.739 & 0.761 & 0.834 & 0.886 \\
$\Delta E(\mathrm{eV})$ & 8.314 & 8.407 & 8.862 & 8.852 & 8.813 \\
$\mu(\mathrm{debyes})$ & 3.426 & 2.350 & 2.205 & 2.103 & 2.071 \\
$\eta(\mathrm{eV})$ & 4.157 & 4.204 & 4.462 & 4.196 & 4.152 \\
$\sigma(\mathrm{eV}-1)$ & 0.241 & 0.238 & 0.224 & 0.238 & 0.240 \\
$-\mathrm{Pi}(\mathrm{eV})$ & 4.884 & 4.943 & 5.222 & 5.030 & 5.038 \\
$\chi(\mathrm{eV})$ & 4.884 & 4.943 & 5.222 & 5.050 & 0.038 \\
$\Delta N(\mathrm{e})$ & 3.112 & 2.987 & 2.746 & 2.687 & 2.613 \\
\hline
\end{tabular}

and after an incubation period, which correspond to the time interval needed by the corrodent to break down the pre-immersion oxide film on the aluminum alloy surface, the volume of evolved $\mathrm{H}_{2}$ gas varies linearly with reaction time. It is also observed from the plots that the volume of hydrogen evolved was reduced on introduction of the inhibitors onto the blank corrodent compared to the free acid and further decreases as the concentration of the inhibitor increases. Corrosion rate and inhibition efficiency values for $\mathrm{Al}-\mathrm{Si}$ alloy in $1 \mathrm{M} \mathrm{HCl}$ in the absence and presence of varying concentrations of the inhibitor at $30{ }^{\circ} \mathrm{C}$ from the hydrogen evolution measurements are given in Table 8. From table, it is seen that the value of corrosion rate was high in the blank acid solution in the absence of the inhibitor. Addition of the inhibitor to the acid solution led to a strong reduction in the corrosion rate of alloy and was found to decrease as the inhibitor concentration increases. Inhibition efficiency and surface coverage increases with increase in the inhibitor concentration. Inhibition efficiency $(\% \eta)$ was calculated using the following equation:

$\% \eta=\left[1-\left(V_{H t} / V_{H t}^{\circ}\right)\right] \times 100$,

where $\left(V_{H t} / V_{H t}^{\circ}\right)$ are the volumes of $\mathrm{H}_{2}$ gas evolved at time $(t)$ for inhibited and uninhibited solutions, respectively. The order of $\% \eta$ was found to decrease in the following sequence: $(1)>(2)>(3)>(4)>(5)$.

\subsection{Quantum Chemical Parameters of Investigated Compounds}

The $E_{\mathrm{HOMO}}$ indicates the ability of the molecule to donate electrons to an appropriated acceptor with empty molecular orbital's, and ELUMO indicates its ability to accept electrons. The lower the value of $E_{\mathrm{LUMO}}$, the more the ability of the molecule is to accept electrons [56-58]. While the higher the value of $E_{\mathrm{HOMO}}$ of the inhibitor, the easier for it to offer electrons to the unoccupied d-orbital of metal surface and the greater its inhibition efficiency. The calculations listed in Table 9 showed that the highest energy $E_{\text {НОмо }}$ is assigned for the compound (1), which is expected to have the highest corrosion inhibition among the investigated compounds. The presence of methoxy group destabilizes the HOMO level which is most observed in the case of compound (1). Therefore, it has the greatest tendency to adsorb on the metal surface and accordingly has the highest inhibition efficiency. This expectation is in a good agreement with the experimental measurements suggesting the highest inhibition efficiency for compound (1) among the other investigated inhibitors. Compound (5)

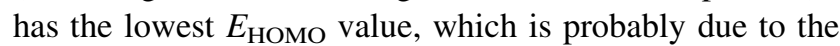
effect of $\mathrm{Br}$ atom that considered as electron withdrawing group as it decreases the electron density on the active centers and also the inhibition efficiency. Furthermore, the HOMO level is mostly localized on the two benzene moiety, indicating that the preferred sites for electrophilic attack at the metal surface are through the nitrogen and oxygen atoms, this means that the two benzene moiety with high coefficients of HOMO density was oriented toward the metal surface, and the adsorption is probably occurred through the p-electrons of the two benzene moiety and the lone pair of nitrogen and oxygen. $\left(E_{\mathrm{LUMO}}-E_{\mathrm{HOMO}}\right)$ energy gap, $(\Delta E)$, which is an important stability index, is applied to develop theoretical models for explaining the structure and conformation barriers in many molecular systems. The smaller is the value of $\Delta E$, the more is the probable inhibition efficiency that the compound has [59-61]. The dipole moment $(\mu)$, electric field, was used to discuss and rationalize the structure [62]. It was observed from Table 9 that compound (1) has the smallest $\left(\mathrm{E}_{\mathrm{LUMO}}-E_{\mathrm{HOMO}}\right)$ energy gap compared with the other molecules. Accordingly, it could be expected that compound (1) has more inclination to adsorb on the metal surface than the other molecules. The higher is the value of $(\mu)$, the more is the probable inhibition efficiency that the compound has. The calculations showed that the highest value of $(\mu)$ is assigned for the compound (1) which has the highest inhibition efficiency. Absolute hardness $(\eta=\Delta E / 2)$ and 


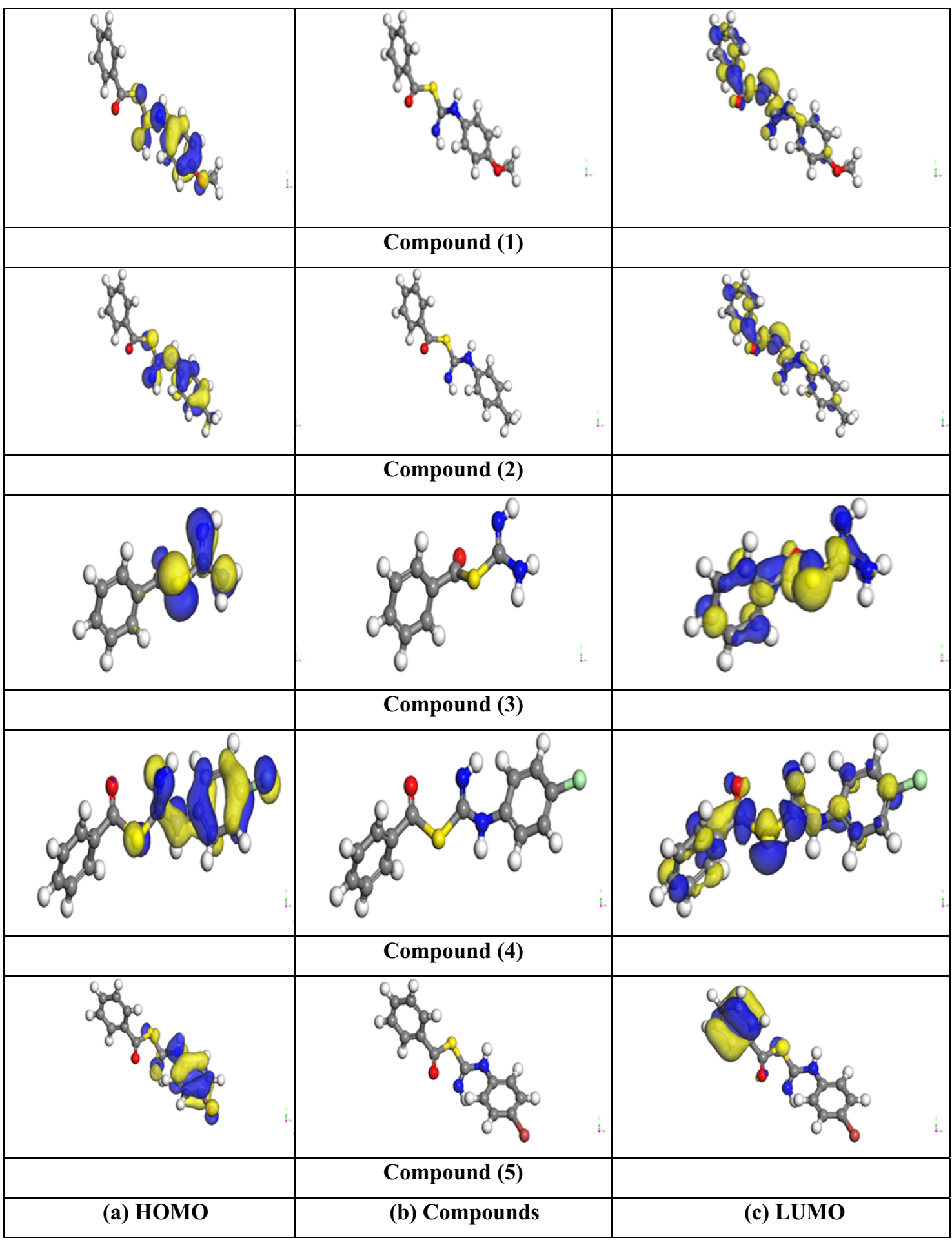

Fig. 9 a HOMO plots of compounds at B3LYP/6-31G (d). b Optimized structures of compounds at B3LYP/6-31G (d). c LUMO plots of compounds at B3LYP/6-31G

softness $(\sigma=1 / \eta)$ are important properties to measure the molecular stability and reactivity. A hard molecule has a large energy gap and a soft molecule has a small energy gap. Soft molecules are more reactive than hard ones because they could easily offer electrons to an acceptor. For the simplest transfer of electrons, adsorption could occur at the part of the molecule where $(\sigma)$, which is a local property, has the highest value [63]. In a corrosion system, 
the inhibitor acts as a Lewis base while the metal acts as a Lewis acid. Bulk metals are soft acids and thus soft base inhibitors are most effective for acidic corrosion of those metals. Accordingly, it is concluded that inhibitor with the highest $(\sigma)$ value has the highest inhibition efficiency that found in compound (1), which is in a good agreement with the experimental data. This is also confirmed from the calculated inhibition efficiencies of molecules as a function of the inhibitor chemical potential $\left(\mathrm{Pi}=\left(E_{\mathrm{HOMO}}+\right.\right.$ $\left.\left.E_{\text {LUMO }}\right) / 2\right)$. The relatively good agreement of $(\mathrm{Pi})$ and $(\Delta N)$ with the inhibition efficiency could be related to the fact that any factor causing an increase in chemical potential would enhance the electronic releasing power of inhibitor molecule. Finally, from Table 9, we found that the $E_{\mathrm{HOMO}}$ and the $E_{\mathrm{LUMO}}$ changed regularly, while the $\Delta E$ decreased with increasing the inhibition efficiency. The inhibition efficiency is related with the changes of the $E_{\mathrm{HOMO}}$ and $E_{\mathrm{LUMO}}$, which suggested that the inhibitors were perhaps either the acceptor or the donor of the electron. That is, there was electron transferring in the interaction between the inhibitor molecules and the metal surface. The $\Delta E$ decreased with increasing the inhibition efficiency, this indicates that the more unstable of the inhibitors, the stronger interaction between the inhibitors and the metal surface. Thus, the interactions are probably physical adsorption, and the interactions between the inhibitors and the metal surface might be ascribed to the hyper conjugation interactions $-\pi$ stacking [64].From the results obtained, we found that the order of $\% \eta$ decreases in the following sequence: (1) $>(2)>(3)>(4)>(5)$, and this agree with the results obtained from the experimental measurements (Fig. 9).

\subsection{Mechanism of Corrosion Inhibition}

In general, these inhibitors may be adsorbed on aluminum alloy surface in their neutral or protonated forms (cationic form). Since it is well known that the aluminum surface is negatively charged in acid solution [65], it is easier for the protonated molecules to approach the negatively charged aluminum alloy surface due to the electrostatic attraction. In case of adsorption, this involves the displacement of water molecules from the aluminum surface and sharing electrons between the hetero-atoms and aluminum. Also, the inhibitor molecules can absorb on aluminum surface on the basis of donor-acceptor interactions between $\pi$-electrons of aromatic rings and vacant $\mathrm{p}$-orbitals of surface aluminum atoms. Thus, we can conclude that inhibition of Al-Si alloy corrosion in $\mathrm{HCl}$ is mainly due to electrostatic interaction. The order of decreasing inhibition efficiency of the compounds from all techniques used is: $(1)>(2)>(3)>(4)>(5)$. Inhibitor (1) is the most efficient inhibitor because of (i) the presence of highly electron donating $\mathrm{p}-\mathrm{OCH}_{3}$ group (with Hammett constant $\sigma=-0.27$ ) [66] which enhances the delocalized $\pi$ electrons on the molecule (ii) also may add an additional active center to the molecule due to its oxygen atom. Inhibitor (2) comes after inhibitor (1) in inhibition efficiency, because the presence of $\mathrm{p}-\mathrm{CH}_{3}$ with $(\sigma=-0.17)$ which contribute less electron density to the molecule and also the absence of oxygen atom so gives less active centers. Inhibitor (3) comes after compounds 1 and 2 in inhibition efficiency, this may be due to the absence of substituent group in para position and presence of $\mathrm{H}$ atom $(\sigma=0.0)$ that contributes no charge density to the molecule. For inhibitors (4 and 5), they are least effective inhibitors because they include $\mathrm{p}-\mathrm{Cl}$ $(+0.22)$ and $\mathrm{p}-\mathrm{Br}(+0.23)$ groups which act as electron withdrawing groups; so they decrease the electron density on the active centers, and hence, the inhibition efficiency will decrease. According to the previous discussion, the nature of substituted group, whether electron donating or withdrawing reflects its effect on the inhibition efficiency.

\section{Conclusions}

The investigated compounds show excellent performance as corrosion inhibitors in $\mathrm{HCl}$ solution. The inhibition efficiency of investigated derivatives follows the order: $1>2>3>4>5$. Polarization studies showed that investigated derivatives behave as mixed-type inhibitors for $\mathrm{Al}-\mathrm{Si}$ alloy in $\mathrm{HCl}$ solution. Impedance studies indicated that $R_{\mathrm{ct}}$ values increased, while $C_{\mathrm{dl}}$ values decreased in the presence of the inhibitors. The adsorption of the investigated inhibitors was found to follow the Langmuir adsorption isotherm. The $\% \eta$ obtained from polarization curves, electrochemical impedance spectroscopy, electrochemical frequency modulation, and hydrogen evolution method is in a good agreement.

\section{References}

1. Rosliza R, Nik WW, Senin HB (2008) The effect of inhibitor on the corrosion of aluminum alloys in acidic solutions. Mater Chem Phys 107:281-288

2. Obot IB, Obi-Egbedi NO (2008) Fluconazole as an inhibitor for aluminum corrosion in $0.1 \mathrm{M} \mathrm{HCl}$. Colloids Surf A 330:207-212

3. Aytac A (2010) $\mathrm{Cu}(\mathrm{II}), \mathrm{Co}(\mathrm{II})$ and $\mathrm{Ni}(\mathrm{II})$ complexes of $-\mathrm{Br}$ and $\mathrm{OCH}_{2} \mathrm{CH}_{3}$ substituted Schiff bases as corrosion inhibitors for aluminum in acidic media. J Mater Sci 45:6812-6818

4. Foad El-Sherbini E, Abd-El-Wahab SM, Deyab MA (2003) Studies on corrosion inhibition of aluminum in $1.0 \mathrm{M} \mathrm{HCl}$ and $1.0 \mathrm{M} \mathrm{H}_{2} \mathrm{SO}_{4}$ solutions by ethoxylated fatty acids. Mater Chem Phys 82:631-637

5. Lukovits I, Kalman E, Zucchi F (2001) Corrosion inhibitorscorrelation between electronic structure and efficiency. Corrosion 57:3-9

6. Brett CMA, Gomes IAR, Martins JPS (1994) The electrochemical behaviour and corrosion of aluminum in chloride media. The effect of inhibitor anions. Corros Sci 36:915-923 
7. El Abedin SZ (2001) Role of chromate, molybdate and tungstate anions on the inhibition of aluminiumin chloride solutions. J Appl Electrochem 31:711-718

8. Mousavifard SM, Nouri PMM, Attar MM, Ramezanzadeh B (2013) The effects of zinc aluminum phosphate (ZPA) and zinc aluminum polyphosphate (ZAPP) mixtures on corrosion inhibition performance of epoxy/polyamide coating. J Ind Eng Chem 19:1031-1039

9. Sherif EM, Park S-M (2005) Effects of 1,5-naphthalenediol on aluminum corrosion as a corrosion inhibitor in $0.50 \mathrm{M} \mathrm{NaCl}$. J Electrochem Soc 152:205-211

10. Natishan PM, McCafferty E, Hubler GK (1988) Surface charge considerations in the pitting of ion-implanted aluminum. J Electrochem Soc 135:321-327

11. Sherif ESM (2011) Corrosion and corrosion inhibition of aluminum in Arabian Gulf seawater and sodium chloride solutions by 3 -amino5- mercapto-1,2,4-triazole. Int J Electrochem Sci 6:479-1492

12. El-Etre AY (2001) Inhibition of acid corrosion of aluminum using vanillin. Corros Sci 43:1031-1039

13. Ogurtsov NA, Pud AA, Kamarchik P, Shapoval GS (2004) Corrosion inhibition of aluminum alloy in chloride mediums by undoped and doped forms of polyaniline. Synth Met 143:43-47

14. Saidman SB, Bessone JB (2002) Electrochemical preparation and characterisation of polypyrrole on aluminium in aqueous solution. J Electroanal Chem 521:87-94

15. Sherif E-SM, Almajid AA (2010) Surface protection of copper in aerated $3.5 \%$ sodium chloride solutions by 3 -amino-5-mercapto1,2,4-triazole as a copper corrosion inhibitor. J Appl Electrochem 40:1555-1562

16. Sherif E-SM (2012) Electrochemical and gravimetric study on the corrosion and corrosion inhibition of pure copper in sodium chloride solutions by two azole derivatives. Int J Electrochem Sci 7:1482-1859

17. Sherif E-SM (2012) Corrosion behavior of copper in $0.50 \mathrm{M}$ hydrochloric acid pickling solutions and its inhibition by 3-amino-1,2,4-triazole and 3-Amino-5-mercapto-1,2,4-triazole. Int J Electrochem Sci 7:1884-1897

18. Sherif E-SM, Erasmus RM, Comins JD (2007) Corrosion of copper in aerated acidic pickling solutions and its inhibition by 3 -amino1,2,4- triazole-5-thiol. J Colloid Interface Sci 306:96-104

19. Sherif E-SM, Erasmus RM, Comins JD (2007) Corrosion of copper in aerated synthetic sea water solutions and its inhibition by 3-amino-1,2,4- triazole. J Colloid Interface Sci 309:470-477

20. Sherif E-SM, Erasmus RM, Comins JD (2007) Effects of 3-amino-1,2,4-triazole on the inhibition of copper corrosion in acidic chloride solutions. J Colloid Interface Sci 311:144-151

21. Sherif ESM, Erasmus RM, Comins JD (2009) Inhibition of corrosion processes on copper in aerated sodium chloride solutions by 5-(3- aminophenyl)-tetrazole. J Appl Electrochem 39:83-91

22. Sherif ESM, Erasmus RM, Comins JD (2008) Inhibition of copper corrosion in acidic chloride pickling solutions by 5-(3aminophenyl)-tetrazole as a corrosion inhibitor. Corros Sci 50:3439-3445

23. Sherif EM, Park S-M (2006) Effects of 2-amino-5-ethylthio-1,3,4thiadiazole on copper corrosion as a corrosion inhibitor in aerated acidic pickling solutions. Electrochim Acta 51:6556-6562

24. Sherif EM, Park S-M (2006) 2-Amino-5-ethyl-1,3,4-thiadiazole as a corrosion inhibitor for copper in $3.0 \%$ NaClsolutions. Corros Sci 48:4065-4079

25. Sherif E-SM (2006) Effects of 2-amino-5-(ethylthio)-1,3,4-thiadiazole on copper corrosion as a corrosion inhibitor in $3 \% \mathrm{NaCl}$ solutions. Appl Surf Sci 252:8615-8623

26. Sherif E-SM (2011) Corrosion and corrosion inhibition of pure iron in neutral chloride solutions by $1,1^{\prime}$-thiocarbonyldiimidazole. Int J Electrochem Sci 6:3077-3092
27. Sherif E-SM (2011) Effects of 5-(3-Aminophenyl)-tetrazole as a corrosion inhibitor on the corrosion of $\mathrm{Mg} / \mathrm{Mn}$ alloy in Arabian Gulf water. Int J Electrochem Sci 6:5372-5387

28. Sherif E-SM, Ahmed AH (2010) Synthesizing new hydrazone derivatives and studying their effects on the inhibition of copper corrosion in sodium chloride solutions. Synth React Inorg Metal Org Nano Metal Chem 40:365-372

29. Sherif ESM (2012) Effects of exposure time on the anodic dissolution of Monel-400 in aerated stagnant sodium chloride solutions. J Solid State Electrochem 16:891-899

30. Sherif ESM (2011) Effects of 5-(3-aminophenyl)-tetrazole on the inhibition of unalloyed iron corrosion in aerated $3.5 \%$ sodium chloride solutions as a corrosion inhibitor. Mater Chem Phys 129:961-967

31. Sherif ESM (2010) Corrosion mitigation of copper in acidic chloride pickling solutions by 2-amino-5-ethyl-1,3,4-thiadiazole. J Mater Eng Perform 19:873-879

32. Brett CMA, Gomes IAR, Martins JPS (1994) The electrochemical behavior and corrosion of aluminium in chloride media. The effect of inhibitor anions. Corros Sci 36:915-923

33. Riggs OL Jr, Nathan CC (eds) (1973) Corrosion inhibitors, 2nd edn. NACE, Houston

34. Pearson RG (1988) Absolute electronegativity and hardness: application to inorganic chemistry. Inorg Chem 27:734-740

35. Onuchukwu AI (1998) The kinetic and mechanism of hydrogen evolution on corroding aluminum alloy in alkaline medium. Mater Chem Phys 25:227-235

36. Umoren SA, Obot IB, Ebenso EE, Okafor PC, Ogbobe O, Oguzie EE (2006) Gum Arabic as potential corrosion inhibitor for aluminum in alkaline medium and its adsorption characteristics. Anti Corros Methods Mater 53:277-282

37. Bockris JOM, Drazic D (1962) The kinetics of deposition and dissolution of iron: effect of alloying impurities. Electrochim Acta 7:293-313

38. Fouda AS, Al-Sarawy A, El-Katori E (2010) Thiazole derivatives as corrosion inhibitors for $\mathrm{C}$-steel in sulphuric acid solution. Eur $\mathrm{J}$ Chem 1(4):312-318

39. Li X, Deng S, Fu H, Mu G (2009) Inhibition effect of 6-benzylaminopurine on the corrosion of cold rolled steel in $\mathrm{H}_{2} \mathrm{SO}_{4}$ solution. Corros Sci 51:620

40. Bessone J, Mayer C, Tuttner K, Lorenz WJ (1983) AC-impedance measurements on aluminum barrier type oxide films. Electrochim Acta 28:171-175

41. Fouda AS, El-TaibHeakal F, Radwan MS (2009) Role of some thiazole derivatives as inhibitors for the corrosion of Carbon steel in $\mathrm{H}_{2} \mathrm{SO}_{4}$. J Appl Electrochem 39:391-402

42. Fouda AS, Mostafa HA, El-TaibHeakal F, Elawady GY (2005) Synergistic influence of iodide ions on the inhibition of corrosion of Carbon steel in sulphuric acid by some aliphatic amines. Corros Sci 47:1988-2004

43. Bentiss F, Bouanis M, Mernari B, Traisnel M, Vezin H, Lagrenee M (2007) Understanding the adsorption of 4H-1,2,4-triazole derivatives on mild steel surface in molar hydrochloric acid. Appl Surf Sci 253:3696-3704

44. Kus E, Mansfeld F (2006) An evaluation of the electrochemical frequency modulation (EFM) technique. Corros Sci 48:965-979

45. McCafferty E, Leidheiser H (eds) (1979) Corrosion control by coating. Science Press, Princeton, p 279

46. Oguzie EE, Ebenso EE (2006) Studies on the corrosion inhibiting effect of Congo red dye-halide mixtures. Pigment Resin Technol $1: 30-35$

47. Villamil RFV, Corio P, Rubin JC, Agostinho SML (1999) Effect of sodium dodecylsulfate on copper corrosion in sulfuric acid media in the absence and presence of benzotriazole. J Electroanal Chem 472:112-119 
48. Kliskic M, Radosevic J, Gridic S (1997) Pyridine and its derivatives as inhibitors of aluminium corrosion in chloride solution. J Appl Electrochem 27:947-952

49. Aramaki K, Hackerman N (1969) Inhibition mechanism of medium-sized olymethyleneimine. J Electrochem Soc 116:568-574

50. Tang L, Li X, Li L, Mu G, Liu G (2006) The effect of 1-(2pyridylazo)-2-naphthol on the corrosion of cold rolled steel in acid media: part 2: inhibitive action in $0.5 \mathrm{M}$ sulfuric acid. Mater Chem Phys 97:301-307

51. Donahuce FM, Noor K (1965) Theory of organic corrosion inhibitors: adsorption and linear free energy relationships electron. J Electrochem Soc 112:886-891

52. Okafor PC, Ikpi ME, Uwah IE, Ebenso EE, Ekpe UJ, Umoren SA (2008) Inhibitory action of Phyllanthus amarus extracts on the corrosion of mild steel in acidic media. Corros Sci 50:2310-2317

53. Oguzie EE (2007) Corrosion inhibition of aluminum in acidic and alkaline media by Sansevieria trifasciata extract. Corros Sci 49:1527-1539

54. Fouda AS, Al Sarawy AA, El Katori EE (2006) Pyrazolone derivatives as corrosion inhibitors for $\mathrm{C}$-steel in hydrochloric acid solution. Desalination 201:1-13

55. Martinez S, Matikos-Hukovic M (2003) A nonlinear kinetic model introduced for the corrosion inhibitive properties of some organic inhibitors. J Appl Electrochem 33:1137-1147

56. Gece G (2008) The use of quantum chemical methods in corrosion inhibitor studies. Corros Sci 50:2981

57. Zarrouka AE, Hammouti B, Dafali A, Bouachrine M, Zarrok H, Boukhris S, Al-Deyab SS (2014) A theoretical study on the inhibition efficiencies of some quinoxalines as corrosion inhibitors of copper in nitric acid. J Saudi Chem. Soc 18:450-455

58. Zhang DQ, Gao LW, Zhou GD (2004) Inhibition of copper corrosion in aerated hydrochloric acid solution by heterocyclic compounds containing a mercapto group. Corros Sci 46:3031-3040

59. Gao G, Liang C (2007) Electrochemical and DFT studies of $\beta$ amino-alcohols as corrosion inhibitors for brass. Electrochim Acta 52(13):4554-4559

60. Feng Y, Chen S, Guo Q, Zhang Y, Liu G (2007) Inhibition of iron corrosion by 5,10,15,20-tetraphenylporphyrin and 5,10,15,20-tetra-(4-chlorophenyl) porphyrinadlayers in $0.5 \mathrm{M} \mathrm{H}_{2} \mathrm{SO}_{4}$ solutions. J Electroanal Chem 602:115

61. Khalil N (2003) Quantum chemical approach of corrosion inhibition. Electrochim Acta 48:2635-2645

62. Martınez S (2002) Inhibitory mechanism of mimosa tannin using molecular modeling and substitutional adsorption isotherms. Mater Chem Phys 77:97

63. Dinnappa RK, Mayanna SM (1982) Benzoic acid and substituted benzoic acids as interfacial corrosion inhibitors for copper in $\mathrm{HClO}_{4}$. J Appl Electrochem 11:111-116

64. Hammett LP (1940) Physical organic chemistry. McGraw-Hill Book Co., New York

65. Desai MN (1972) Corrosion inhibitors for aluminum alloys. A review on corrosion inhibitors of the alloys Al-2S, Al-3S, Al-57S, and $\mathrm{A} 165 \mathrm{~S}$ in $\mathrm{HCl}, \mathrm{H}_{2} \mathrm{SO}_{4}, \mathrm{HOAc}, \mathrm{H}_{2} \mathrm{C}_{2} \mathrm{O}_{4}$ and $\mathrm{NaOH}$. Werkst $\mathrm{U}$ Korros 23(6):475-482 